\title{
Construção de um Instrumento para Avaliação do Conhecimento sobre Ferida Neoplásica Maligna
}

doi: https://doi.org/10.32635/2176-9745.RBC.2022v68n1.1377

\author{
Construction of an Instrument to Assess Knowledge about Malignant Neoplastic Wounds \\ Construcción de un Instrumento para Evaluar Conocimientos sobre Heridas Neoplásicas Malignas
}

Lilian de Lana Bernardino'; Maria das Graças Silva Matsubara²

RESUMO

Introdução: Feridas neoplásicas malignas (FNM), também denominadas de lesōes oncológicas, tumorais ou fungoides, ocorrem pela infiltraçáo das células malignas do tumor nas estruturas da pele. Objetivo: Construir e validar um questionário para avaliar o conhecimento do enfermeiro especialista em Oncologia sobre o cuidado com o paciente portador de FNM. Método: Estudo transversal, com abordagem quantitativa, dividido em duas etapas. A etapa 1 consiste na elaboração do questionário e a etapa 2 compreende a validação. Resultados: Todos os 11 especialistas convidados aceitaram participar do estudo, sendo realizada a classificação segundo critérios propostos no processo de elaboração e validação, mostrando pontuação média de 11 . Entre os especialistas, $18,18 \%$ eram estomaterapeutas, $18,18 \%$ mestres, $54,55 \%$ doutores e 9,09\% pós-doutores. Foi elaborado um questionário contendo 18 questóes de múltipla escolha com quatro opçóes de respostas abrangendo os seguintes temas: incidência, definiçáo, processo de oncogênese e FNM, características e sintomatologia, estadiamento, tratamento e intervenções de enfermagem, intervenções básicas e específicas no manejo da FNM, proteção da pele periferida e especificidade da FNM comparada a feridas de outras etiologias. A validação foi realizada por meio do índice de concordância entre os avaliadores usando o coeficiente de Kendall, com resultado geral igual a 0,0941, indicando um bom grau de concordância. Conclusáo: $\mathrm{O}$ presente estudo contribui para a área de Enfermagem Oncológica tanto no que tange às instituiçóes de ensino que possuem o programa de pós-graduação em Oncologia como às instituiçóes de saúde com o intuito de direcionar o desenvolvimento de programas de educação permanente.

Palavras-chave: enfermagem oncológica; cicatrização; ferimentos e lesôes; cuidados paliativos; neoplasias.

\section{ABSTRACT}

Introduction: Malignant neoplastic wounds (MNW), also called oncological, tumoral or fungoid lesions, occur due to the infiltration of malignant tumor cells in skin structures. Objective: To build and validate a questionnaire to assess the knowledge of nurses specialized in Oncology about the care of patients with MNW. Method: Cross-sectional, quantitative approachstudy, divided int two stages. Step 1 consists of preparing the questionnaire and step 2 comprises the validation. Results: All 11 invited specialists agreed to participate in the study, being classified according to the criteria proposed, showing an average score of 11 . Among the specialists, $18.18 \%$ were stomal therapists, $18.18 \%$ were Masters, $54.55 \%$ were Ph.D graduated and $9.09 \%$ postdoctoral fellows. A 4 response options questionnaire containing 18 multiple-choice questions was developed, covering the following topics: incidence, definition, oncogenesis process and MNW, characteristics and symptoms, staging, treatment and nursing interventions, basic and specific interventions in the management of MNW, peripheral skin protection and specificity of MNW compared with wounds of other etiologies. Validation was performed through the concordance coefficient among the evaluators using Kendall's coefficient, with an overall result equal to 0.0941 , indicating a good degree of concordance. Conclusion: The present study contributes to the Oncology Nursing area both in terms of educational institutions that have a postgraduate program in Oncology and health institutions with the aim of guiding the development of permanent education programs.

Key words: oncology nursing; wound healing; wounds and injuries; palliative care; neoplasms.
RESUMEN

Introducción: Las heridas neoplásicas malignas (HNM), también llamadas lesiones oncológicas, tumorales o fungoides, se producen por la infiltración de células tumorales malignas en estructuras cutáneas. Objetivo: Construir y validar un cuestionario para evaluar el conocimiento de enfermeras especializadas en Oncología sobre el cuidado de pacientes con HNM. Método: Estudio transversal con enfoque cuantitativo, dividido en dos etapas. El paso 1 consiste en preparar el cuestionario y el paso 2 comprende la validación. Resultados: Los 11 especialistas invitados aceptaron participar en el estudio, siendo clasificados según los criterios propuestos, presentando una puntuación media de 11 . Entre los especialistas, el 18,18\% eran terapeutas estomales, el 18,18\% maestros, el 54,55\% médicos y $9,09 \%$ becarios postdoctorales. Se desarrolló un cuestionario que contiene 18 preguntas de opción múltiple con 4 opciones de respuesta, cubriendo los siguientes temas: incidencia, definición, proceso de oncogénesis y HNM, características y síntomas, estadificación, tratamiento e intervenciones de enfermería, intervenciones básicas y específicas en el manejo de la HNM, protección de la piel periférica y especificidad de la HNM en comparación con heridas de otras etiologías. La validación se realizó mediante el índice de concordancia entre los evaluadores utilizando el coeficiente de Kendall, con un resultado global igual a 0,0941, lo que indica un buen grado de concordancia. Conclusión: Este estudio aporta al área de Enfermería Oncológica tanto en cuanto a las instituciones educativas que cuentan con un programa de posgrado en Oncología como a las instituciones de salud con el objetivo de orientar el desarrollo de programas de educación permanente. Palabras clave: enfermería oncológica; cicatrización de heridas; heridas y lesiones; cuidados paliativos; neoplasias.

'Instituto do Câncer do Estado de São Paulo (ICESP). São Paulo (SP), Brasil. E-mail: lilian.lana@hc.fm.usp.br. Orcid iD: https://orcid.org/0000-0002-4686-7609 ${ }^{2}$ A. C. Camargo Cancer Center. São Paulo (SP), Brasil. E-mail: maria.matsubara@accamargo.org.br. Orcid iD: https://orcid.org/0000-0002-9943-6722 Endereço para correspondência: Lilian de Lana Bernardino. Rua Major Cardim, 1780 - Vila Suissa. Ribeirão Pires (SP), Brasil. CEP 09423-500. 


\section{INTRODUÇÃO}

O câncer é um dos principais fatores responsáveis pela mudança do perfil de adoecimento da população brasileira ${ }^{1}$. No Brasil, estima-se, para cada ano do triênio 2020-2022, o surgimento de 625 mil casos novos de câncer, tendo por maior incidência, exceto pele não melanoma (177 mil), os cânceres de mama (66 mil), próstata (66 mil), cólon e reto (41 mil), pulmão (30 mil) e estômago $(21 \mathrm{mil})^{2}$.

Em se tratando de pacientes acometidos pelo câncer, cerca de $5 \%$ a $10 \%$ desenvolverão feridas em consequência de um tumor primário ou por meio de metástases, repercutindo diretamente na qualidade de vida do paciente, pois resulta em dor, sentimento de incapacidade, mudanças na autoestima, na autoimagem e mudanças sociais, decorrentes da necessidade frequente de hospitalização e afastamento do convívio social ${ }^{3}$.

Entre os tumores que possuem maiores incidências para ocasionar as feridas neoplásicas malignas (FNM), podem ser citados os cânceres de mama e de cabeça e pescoço. Entretanto, estas ainda podem ser originadas dos cânceres pulmonar, ovariano, geniturinário, sarcomas e melanomas ${ }^{4}$.

As FNM, também denominadas de lesões oncológicas, tumorais ou fungoides (aspecto de cogumelo), ocorrem pela infiltração das células malignas do tumor nas estruturas da pele, tendo por consequência a formação de uma ferida evolutivamente exofítica por meio da quebra da integridade tissular, resultante da proliferação celular desordenada, causada pelo processo de oncogênese $e^{5}$.

Esse processo é responsável pelas peculiaridades na sintomatologia de feridas dessa etiologia, por provocar o crescimento do tumor, a neovascularização e a invasão de células tumorais nos tecidos saudáveis, o que acarreta a oclusão de vasos sanguíneos, reduz a oferta de oxigênio, provoca hipóxia, com consequente formação de tecido tumoral necrótico, que pode estar contaminado por bactérias, resultando no aumento de exsudato e odor fétido ${ }^{3}$.

Pacientes acometidos por uma doença terminal, portadores de FNM, exprimem um sentimento de angústia, visto que são lesões desfiguradas, não havendo possibilidade de cicatrização e que manifestam sintomas difíceis de serem controlados 5 .

Entre os principais sinais e sintomas, estão: dor, odor fétido, exsudato, sangramento, prurido, infecçóes, fístulas e desfiguramento corporal progressivo. Portanto, é primordial o manejo adequado desses sinais e sintomas, pois o paciente, que recebe a notícia do diagnóstico de câncer, vivencia sofrimento físico e psicológico, isolamento social, imagem corporal prejudicada e constrangimento em virtude da presença dessas lesóes, o que resulta em um sentimento de enojamento de si mesmo ${ }^{4,6}$.

A dor ocorre por causa do processo de crescimento tumoral desordenado e acelerado, invadindo ou exercendo pressão sobre estruturas e terminaçôes nervosas, causando dor neuropática. Contudo, também pode ser ocasionada pelo manejo incorreto durante a realização da troca de curativo ${ }^{4}$.

O sangramento está diretamente relacionado à fisiopatologia e a elementos correlacionados à malignidade, tais como a trombocitopenia e coagulação disseminada. Também pode ser relativo ao desiquilíbrio fisiológico, decorrente do crescimento tumoral, tendo por consequência a diminuição da função plaquetária, o aumento da rede neovascular friável e, ainda, da radioterapia, traumas durante o processo de troca de curativos, erosão dos vasos adjuntos em razão da proliferação das células malignas ou até mesmo da ruptura dos principais vasos tumorais ${ }^{4,7}$.

O exsudato é atribuído ao processo inflamatório e pela vasodilataçáo decorrente do aumento da permeabilidade capilar na ferida, diretamente relacionado ao catabolismo tecidual provocado pelas proteases bacterianas ${ }^{7}$.

Outro sintoma muito frequente na FNM é o odor, que impacta de forma negativa na qualidade de vida do paciente e de seus cuidadores, ocasionando sentimento de culpa e repulsa, suscitando o isolamento social e até a depressão. O odor está associado ao crescimento desordenado do tumor, no qual se origina uma massa tumoral necrótica no leito da ferida, geralmente precedente de contaminação mediante microrganismos aeróbios e anaeróbios. Essas bactérias exalam ácidos graxos voláteis, como o ácido acético e caproico e os gases putrescina e cadaverina, os quais são responsáveis pelo odor fétido 7 .

Raramente ocorre a presença de prurido, entretanto, surgem com maior frequência em casos de câncer de mama e de infiltração cutânea, relacionados à liberação de histaminas pelo processo inflamatório provocado pelo crescimento agressivo da lesão tumoral ${ }^{4}$.

O tratamento das FNM está relacionado à terapia da doença de base, porém, o manejo é atribuiçáo do enfermeiro. Os cuidados desses pacientes exigem conhecimento do profissional quanto à etiologia oncológica, particularidades, estadiamento da lesão, estado biopsicossocial do paciente, assim como produtos e coberturas específicas para o manejo dos sinais e sintomas. Diante disso, é crucial que o enfermeiro possua competência e habilidade para avaliar e manejar as especificidades identificadas nas FNM, propiciando ao paciente e à família uma assistência integral ${ }^{5}$.

Outro ponto importante, que também precede à responsabilidade dos enfermeiros na prestação de cuidados, diz respeito à consciência do impacto físico 
e psicológico que essas feridas provocam na vida dos pacientes oncológicos, sendo necessária a capacitação para promover um cuidado apropriado por meio da escolha adequada no uso de coberturas, visando ao manejo dos sintomas apresentados, reduzindo o impacto da doença $\mathrm{e}$ melhorando a qualidade de vida desses pacientes ${ }^{6}$.

Entre os membros da equipe de saúde, o enfermeiro exerce um papel de extrema importância no manejo da FNM, sendo de sua responsabilidade orientar e supervisionar a equipe de enfermagem, atuando diretamente na avaliação, indicação e execução do tratamento adequado. Assim, sendo primordial que este possua conhecimento e habilidade técnica para avaliar e controlar sintomas de feridas dessa etiologia, a fim de propiciar uma assistência integral e individualizada ao portador e seus familiares ${ }^{8}$.

Os cuidados relacionados às FNM são específicos e diferem das orientaçôes aplicadas às feridas de outras etiologias, por visar ao controle dos sintomas em detrimento da cicatrização. Nesse contexto, os estudos atuais salientam a necessidade de desenvolver pesquisas sobre a temática, visando a validar protocolos específicos para um melhor manejo dos sintomas, aperfeiçoando o cuidado e reduzindo o estresse vivenciado por esses pacientes, familiares e profissionais de saúde $\mathrm{e}^{6}$.

Com base na complexidade do paciente oncológico portador de FNM, além da necessidade de compreender o conhecimento do enfermeiro especialista em Oncologia acerca do tema, uma vez que esse profissional é o responsável pelo planejamento da assistência aos pacientes com feridas, esta pesquisa possui como pergunta norteadora: "quais informaçôes técnico-científicas são importantes para avaliar o conhecimento do enfermeiro especialista em Oncologia quanto ao cuidado com o paciente portador de FNM?" Para responder a essa pergunta, o presente estudo tem como objetivo construir e validar um questionário para avaliar o conhecimento do enfermeiro especialista em Oncologia sobre o cuidado com o paciente portador de FNM.

\section{MÉTODO}

Trata-se de um estudo transversal, com abordagem quantitativa, caracterizado por investigar, organizar e analisar dados para construir e validar um instrumento para avaliar o conhecimento de enfermeiros, cuja populaçáo foi composta por experts sobre FNM, dividido em duas etapas, a elaboração e validaçáo do instrumento.

Alguns critérios foram descritos para que um enfermeiro seja considerado expert em FNM. Cada critério descrito apresenta uma pontuação, sendo que, para ser considerado expert, necessita obter o mínimo de cinco pontos (critérios/pontos: titulação de mestre em enfermagem: 4; titulação de mestre em enfermagem com dissertação direcionada a conteúdo relevante do tema FNM: 1; publicaçáo de artigo sobre FNM em periódicos de referência: 2; artigo publicado sobre feridas e com conteúdo relevante à área: 2; titulação de doutor na área da Oncologia: 2; experiência clínica de, pelo menos, um ano na área de Oncologia: 1; e certificado (especialização) de Estomaterapia e Dermatologia em Enfermagem: 2). Quanto maior a pontuação, maior será a força de evidência da avaliação ${ }^{9}$.

A amostra foi constituída por 11 enfermeiros de nacionalidade brasileira que possuíam no mínimo titulação acadêmica de especialista na área de Estomaterapia e Dermatologia, que atuavam na área da Oncologia. Foram excluídos os sujeitos que apresentaram pontuaçáo inferior a cinco pontos nos critérios estabelecidos por Fehring ${ }^{10}$, em relação à seleção de experts. A seleção dos sujeitos foi feita por meio de busca ativa de profissionais experts das áreas supracitadas, na Plataforma Lattes, do Conselho Nacional de Desenvolvimento Científico e Tecnológico (CNPq) Currículo Lattes e Diretório de Grupos de Pesquisa.

Optou-se por número ímpar para facilitar a análise, o que impossibilitou o empate. O contato aconteceu por meio de correio eletrônico, com o intuito de expor os objetivos, método de estudo e acordar prazo para entrega do conteúdo avaliado, sendo enviados a carta-convite para a avaliação e o Termo de Consentimento Livre Esclarecido (TCLE).

O questionário foi aplicado por meio do programa Google Forms ${ }^{\circledR}$, sendo enviado para os enfermeiros por e-mail, convidando-os para participar do estudo, descrevendo o seu objetivo e contendo o link para acesso ao questionário. Na primeira tela do programa Google Forms $^{\circledR}$, foi inserido o TCLE, sendo considerado como "aceito" quando o enfermeiro prosseguisse às demais telas, nas quais foram apresentadas a primeira parte, contendo os dados sociodemográficos, incluindo formação acadêmica e tempo de atuação em Oncologia, e o questionário com as 18 questốes a serem avaliadas por meio de uma escala Likert equilibrada, par (de 1 a 4), variando do "Concordo Totalmente" ao "Discordo Totalmente" e, também, um espaço para o detalhamento de sugestóes. O período para avaliação do questionário foi de 1 a 30 de agosto de 2019 .

\section{DESENHO DA ETAPA 1: CONSTRUÇÃO DO QUESTIONÁRIO}

Foi elaborado um questionário contendo 18 questôes, a partir dos conteúdos presentes em referências variadas, incluindo artigos científicos e livros, utilizando-se os descritores em Ciências da Saúde (DeCS), usando o operador boleano AND entre os descritores citados: enfermagem oncológica; cuidados paliativos; cicatrização 
de feridas; neoplasias; ferimentos e lesôes; qualidade de vida, nas bases de dados e/ou bibliotecas eletrônicas LILACS, MEDLINE (PubMed), IBECS, SciELO, Biblioteca Cochrane e Google Acadêmico. A definição pelo número de questôes está embasada no conteúdo, conforme busca em literatura, a qual abarca os tópicos pertinentes para o tema FNM.

Essa fase de construção foi concluída e a validação operacionalizada após a aprovação do projeto pelo Comitê de Ética em Pesquisa (CEP).

\section{DESENHO DA ETAPA 2: VALIDAÇÃO DO QUESTIONÁRIO}

Para a validaçáo do questionário, empregou-se o método de validade do conteúdo ou avaliação opinativa, por meio de opiniáo de especialistas que nesta pesquisa foram denominados de juízes.

O objetivo dessa etapa foi produzir a versão do questionário sobre o olhar do especialista.

A etapa de validação do questionário compreendeu a aplicação da técnica Delphi. A finalidade desse método foi buscar consenso entre os especialistas acerca das diferentes questóes, tendo como diretriz as perguntas do questionário. Solicitou-se a avaliação quanto à equivalência semântica, idiomática e conceitual ${ }^{11,12}$.

Para verificar o nível de concordância dos especialistas, foi inserido, abaixo de cada questão do questionário, uma escala Likert, conforme mencionado anteriormente. Esse tipo de escala requer que o avaliador indique seu grau de concordância ou discordância com declarações relativas ao que se está medindo ${ }^{13}$.

Os resultados foram analisados com revisão das questóes citadas para correção, considerando todos os pareceres fornecidos. Em uma segunda rodada, foi reenviado o questionário corrigido e encaminhada uma carta contendo tabulaçáo dos resultados com uso da escala de Likert e descrição das alteraçôes realizadas nas questôes mais citadas e/ou de maior relevância para o parecer final dos especialistas.

A validade de conteúdo, referente à concordância dos juízes, foi avaliada por meio do W. de Kendall. O resultado deste teste apresenta um valor que varia de 0 , significando total discordância entre os avaliadores, e 1, significando total concordância entre os avaliadores. Para a avaliação de concordância, foi adotado o W. de Kendal, pois esse método calcula a concordância entre três ou mais sujeitos, considerando como eles classificam uma série de temas de acordo com uma característica particular ${ }^{14}$.

A realização desta pesquisa precedeu-se da apreciação e aprovação do Comitê de Ética em Pesquisa sob o número de protocolo 3.458.402, de acordo com as diretrizes e normas regulamentadoras de pesquisa envolvendo seres humanos, Resolução CNS 510/16 ${ }^{15}$.

\section{RESULTADOS}

Foram enviados 11 convites para enfermeiros qualificados para que pudessem participar como expert. Todos os convidados responderam à avaliação do questionário.

A maioria dos sujeitos cursou doutorado $(63,6 \%)$, sendo um deste com pós-doutorado, seguido de 18,1\% com titulação de mestre e $18,1 \%$ de especialista em estomaterapia. A média de experiência na área relacionada à temática foi de 9,6 anos, variando de 2 a 24 anos.

A Tabela 1 apresenta o tempo de atuação em Oncologia dos juízes participantes da etapa de validação do questionário.

Tabela 1. Tempo de atuação em Oncologia dos juízes participantes da etapa de validação do questionário sobre FNM. São Paulo, 2021

\begin{tabular}{cc|}
\hline Tempo de atuação na Oncologia & $\%$ \\
\hline 2 a 4 anos & 45,4 \\
5 a 7 anos & 9,0 \\
8 a 10 anos & 18,1 \\
11 a 13 anos & 9,0 \\
\hline Maior do que 17 anos & 18,1 \\
\hline
\end{tabular}

A classificaçáo segundo critérios propostos por Fehring ${ }^{10}$ obteve pontuação média de 11 pontos, conforme detalhado na Tabela 2.

Foram elaboradas 18 questóes de múltipla escolha com quatro opçóes de respostas sobre os seguintes temas: incidência, definição, processo de oncogênese e FNM, características e sintomatologia, estadiamento, tratamento e intervenções de enfermagem, intervençóes básicas e específicas no manejo da FNM, proteção da pele periferida e especificidade da FNM comparada a feridas de outras etiologias.

O Quadro 1 apresenta o instrumento contendo as 18 questôes construídas e validadas.

$\mathrm{Na}$ etapa 2, para a validação do questionário, foram realizadas modificaçóes nas 18 questôes, sendo alterados o enunciado e as opçôes de resposta de oito questôes; seis tiveram mudança no enunciado e quatro nas opçôes de respostas. As principais alteraçóes estão relacionadas com os termos técnicos peculiares na Oncologia e manejo da FNM, tais como "crescimento tumoral rápido e desordenado" por "infiltração de células neoplásicas no tecido conjuntivo"; "frágeis e ingurgitados" para "dilatados"; "estádio" por "estadiamento"; "evitar o desbridamento" por "debridar cirurgicamente".

A validação do questionário contendo indagaçóes técnico-científicas específicas sobre o tema FNM foi feita 
Tabela 2. Classificação dos juízes participantes da etapa de validação do questionário sobre FNM. São Paulo, 2021

\begin{tabular}{|c|c|c|c|c|c|c|c|c|c|c|c|c|}
\hline Especialistas & $\begin{array}{l}\text { Valor } \\
\text { referência }\end{array}$ & $\begin{array}{c}\text { Juiz } \\
1\end{array}$ & $\begin{array}{c}\text { Juiz } \\
2\end{array}$ & $\begin{array}{c}\text { Juiz } \\
3\end{array}$ & $\begin{array}{c}\text { Juiz } \\
4\end{array}$ & $\begin{array}{c}\text { Juiz } \\
5\end{array}$ & $\begin{array}{c}\text { Juiz } \\
6\end{array}$ & $\begin{array}{c}\text { Juiz } \\
7\end{array}$ & $\begin{array}{c}\text { Juiz } \\
8\end{array}$ & $\begin{array}{c}\text { Juiz } \\
9\end{array}$ & $\begin{array}{c}\text { Juiz } \\
10\end{array}$ & $\begin{array}{c}\text { Juiz } \\
11\end{array}$ \\
\hline Titulação de mestre & 4 & 4 & 4 & 4 & 4 & 4 & 4 & 4 & 4 & 4 & - & - \\
\hline $\begin{array}{l}\text { Titulação de mestre na } \\
\text { área de interesse do } \\
\text { estudo* }\end{array}$ & 1 & - & - & - & - & - & - & - & - & - & - & - \\
\hline $\begin{array}{l}\text { Tese de doutorado na } \\
\text { área de interesse do } \\
\text { estudo* }\end{array}$ & 2 & 2 & 2 & - & 2 & 2 & 2 & 2 & 2 & - & - & - \\
\hline $\begin{array}{l}\text { Prática clínica de pelo } \\
\text { menos um ano no tema } \\
\text { de interesse do estudo* }\end{array}$ & 1 & 1 & 1 & 1 & 1 & 1 & 1 & 1 & 1 & 1 & 1 & 1 \\
\hline $\begin{array}{l}\text { Especialização no tema } \\
\text { de interesse do estudo* }\end{array}$ & 2 & 2 & 2 & 2 & 2 & 2 & 2 & 2 & 2 & 2 & 2 & 2 \\
\hline $\begin{array}{l}\text { Publicação de pesquisa } \\
\text { relevante para a área de } \\
\text { interesse do estudo* }\end{array}$ & 2 & 2 & 2 & 2 & 2 & 2 & - & 2 & - & - & 2 & 2 \\
\hline $\begin{array}{l}\text { Publicação de artigo } \\
\text { sobre a área de } \\
\text { interesse do estudo* } \\
\text { em periódico de } \\
\text { referência }\end{array}$ & 2 & 2 & 2 & 2 & 2 & 2 & 2 & 2 & - & - & - & - \\
\hline
\end{tabular}

$\left(^{*}\right)$ Área de interesse do estudo: ferida neoplásica maligna.

Quadro 1. Questionário de avaliação do conhecimento do enfermeiro especialista em Oncologia sobre FNM, São Paulo, 2021

1. Em relação aos tumores que possuem maior incidência para ocasionar as feridas neoplásicas malignas, assinale a opção CORRETA:

a) Mama, pulmonar e colorretal

b) Cabeça e pescoço e mama

c) Colorretal, geniturinário e linfoma não Hodgkin

d) Sarcomas, colorretal e mama

2. As feridas neoplásicas malignas são definidas como:

a) Infiltração das células malignas nas estruturas da pele, incluindo vasos sanguíneos e/ou linfáticos

b) Alteração fisiológica na multiplicação das células derivadas de tumor benigno primário e/ou metastáticos

c) Interrupção na continuidade da pele que afeta sua integridade, sendo relacionada exclusivamente ao processo metastático

d) Deformidade ou lesão que pode ser superficial ou profunda, fechada ou aberta, simples ou complexa, resultado de um processo inflamatório crônico

3. Escolha a opção CORRETA em relação ao processo de oncogênese das feridas neoplásicas malignas:

a) Resultado do déficit de oxigênio e nutrientes para as extremidades da pele

b) Decorrente do crescimento tumoral, da neovascularização e da invasão de tecidos saudáveis, respectivamente

c) Resultante da pressão do tumor entre proeminências ósseas, levando a uma isquemia local e aumento do risco de metástase

d) Consequência de um processo inflamatório, decorrente da infiltração do tumor nas estruturas da pele 
4. A dor é um sintoma frequentemente relacionado à ferida neoplásica maligna. Considerando tal informação, escolha a opção que descreve as possíveis causas da dor em feridas dessa etiologia:

a) Decorrente do quadro infeccioso ocasionado pelo manejo e escolha inadequada de curativo ou cobertura

b) Relacionada a afecções traumáticas, infecciosas ou inflamatórias resultante da infiltração de células neoplásicas no tecido conjuntivo

c) Consequência do crescimento tumoral rápido que invade e exerce pressão sobre estruturas e terminações nervosas e/ou pelo manuseio inadequado durante a troca de curativo

d) Relacionada à exacerbação inflamatória e, também, associada à ansiedade e antecipação da dor durante o seu manejo

5. O odor é considerado o sintoma mais castigante dos pacientes com feridas neoplásicas malignas, em decorrência da sensação de náuseas e do isolamento social imputado ao paciente. Escolha a opção que justifique a origem desse sintoma:

a) Destruição de camadas cutâneas, tais como epiderme e derme, o que pode atingir estruturas anatômicas profundas

b) Dificuldade de respiração tecidual, decorrente da neovascularização prejudicada em virtude da massa tumoral

c) Colonização de bactérias presentes na microbiota transitória da pele, acometida pela doença neoplásica maligna

d) Presença de tecido desvitalizado e mistura de gases voláteis (putrescina, cadaverina), produzidos por bactérias anaeróbicas e aeróbicas presentes no leito da ferida

6. O sangramento em ferida neoplásica maligna pode estar associado à radioterapia e traumas durante a remoção do curativo. Porém, outros fatores também propiciam o desenvolvimento desse evento, entre os quais podem ser citados:

a) Desequilíbrio fisiológico, diminuição da função plaquetária, rede neovascular friável, ruptura de vasos situados no tumor

b) Processo inflamatório, flutuações no fluxo sanguíneo, ruptura de vasos situados no tumor, crescimento tumoral acelerado

c) Degeneração da base da membrana das células cancerígenas, ação de enzimas hidrolíticas, diminuição da função plaquetária, técnicas impróprias de limpeza

d) Capilares dilatados, interação da flora bacteriana, aumento da função plaquetária e da permeabilidade capilar

7. O exsudato, além de provocar desconforto nos pacientes com feridas neoplásicas malignas, também pode contribuir para a presença e/ou exacerbação do odor. Portanto, se pode afirmar que a causa do aumento de exsudato está relacionada a:

a) Processo infeccioso, aumento da permeabilidade capilar, presença de tecido desvitalizado e prurido

b) Profundidade expressiva, processo infeccioso e inflamatório e hipóxia provocada pelo processo tumoral

c) Aumento da permeabilidade capilar, liberação de gases voláteis e debilidade neovascular do tumor

d) Secreção do fator de permeabilidade vascular, liberação de histaminas e infiltração cutânea por células malignas

8. O prurido é um sintoma presente, particularmente, nos pacientes portadores de feridas neoplásicas malignas com câncer de mama e na infiltração cutânea. Escolha a opção na qual esse sintoma está correlacionado:

a) Processo inflamatório e liberação de histaminas

b) Colonização de bactérias anaeróbias e enzimas proteolíticas

c) Fístulas e liberação de exsudato

d) Processo de oncogênese e ácidos voláteis

9. Mulher, 48 anos, portadora de carcinoma ductal invasivo, apresenta ferida neoplásica maligna na mama esquerda, envolvendo a epiderme, derme e subcutâneo, com profundidade regular, mas com saliências e formação irregular, friável, com áreas de ulcerações e tecido necrótico liquefeito, odor fétido, exsudativa, já com aspecto vegetativo tipo couve-flor. Analise a descrição acima e escolha a opção que corresponde ao estadiamento da ferida conforme a classificação do INCA:

a) Estádio II

b) Estádio IV

c) Estádio I

d) Estádio III 
10. As intervenções básicas relacionadas à assistência de enfermagem quanto ao manejo da ferida neoplásica maligna têm por objetivo:

a) Controlar sinais e sintomas, não tendo por objetivo a cicatrização

b) Favorecer o processo de cicatrização e o bem-estar emocional

c) Promover cicatrização e minimizar problemas físicos e psicológicos

d) Favorecer a cicatrização e prevenir o aparecimento de novas lesões

11. Mulher, 54 anos, apresenta ferida neoplásica maligna de aspecto couve-flor em regiáo da mama, apresenta dor frequente durante o manejo da ferida, mantém prescrição com opioide via endovenosa em caso de necessidade. Ao realizar o curativo dessa paciente, deve-se:

a) Administrar opioide via endovenosa, 1 hora antes de realizar o curativo

b) Administrar opioide segundo a prescrição de horário já preestabelecida

c) Comunicar equipe médica responsável solicitando prescrição via tópica, devido à via endovenosa não ser tão eficaz

d) Administrar opioide via endovenosa, 5 minutos antes de realizar o curativo

12. Paciente com ferida neoplásica maligna em região cervical apresenta odor nauseante afastando do convívio de seus familiares e amigos. Foi solicitada avaliação para esse paciente. Para tanto, escolha a opção que corresponda ao manejo desse sintoma:

a) Metronidazol tópico e/ou sistêmico, ácido graxo essencial, curativo de carvão ativado

b) Metronidazol sistêmico, metronidazol tópico e/ou agentes antimicrobianos, curativo de carvão ativado

c) Papaína, metronidazol tópico e/ou sistêmico, curativo de carvão ativado

d) Papaína, polihexametileno biguanida, alginato de cálcio

13. Homem, 57 anos, portador de carcinoma epidermoide escamoso em regiáo esofágica, apresenta ferida neoplásica em região de pescoço com odor fétido, mesmo com o curativo oclusivo. Com base no caso acima, escolha a opção que classifique o odor de acordo a classificação do INCA:

a) Grau 0

b) Grau 1

c) Grau 2

d) Grau 3

14. Paciente do sexo feminino, com ferida neoplásica maligna com sangramento ativo, necessita de conduta para controle imediato. Escolha a opção que corresponda à conduta adequada:

a) Compressão local com chumaço de gaze, compressa ou toalha

b) Aplicação de espuma impregnada com prata

c) Compressa morna embebida em ácido graxo essencial

d) Aplicação de nitrato de prata

15. Homem de 64 anos, com adenocarcinoma de estômago, apresenta ferida neoplásica maligna em região hipogástrica, com perda tecidual e grande quantidade de exsudato. Escolha a opção que corresponda ao manejo desse sintoma:

a) Alginato de cálcio e/ou curativo absortivo contendo carvão ativado e compressa de gaze como cobertura secundária

b) Hidrogel e cobertura secundária contendo carvão ativado e/ou alginato de cálcio

c) Placa de hidrocoloide e/ou hidrofibra e compressa de gaze como cobertura secundária

d) Hidrogel e/ou espuma impregnada com prata e compressa de gaze como cobertura secundária

16. Mulher, 48 anos, apresenta ferida neoplásica maligna em mama esquerda, refere prurido intenso em região perilesão. Considerando sintomatologia referida, escolha a opção que corresponda ao manejo desse sintoma:

a) Banho de aspersão com chá de camomila, prescrição médica de sulfadiazina de prata

b) Investigar a causa, prescrição médica tópica de corticoide e avaliar necessidade de terapêutica sistêmica

c) Prescrição sistêmica de anti-inflamatório, banho de aspersão com chá de camomila morno prolongado

d) Investigar a causa, prescrição tópica de anti-inflamatório 
17. Paciente do sexo feminino, 32 anos, portadora sarcoma de partes moles, em acompanhamento ambulatorial, apresenta ferida neoplásica maligna na região inguinal à esquerda, em uso de sulfadiazina de prata, com exsudato em grande quantidade, pele perilesão hiperemiada, referindo extremo desconforto nessa região. Portanto, como orientação para cuidados em domicílio visando à proteção da pele perilesão, esta deverá receber as seguintes orientações:

a) Uso de creme à base de corticoide para evitar infecções e troca do curativo a cada 24 horas

b) Uso de óxido de zinco como barreira protetora e troca do curativo a cada 12 horas

c) Uso de hidrogel para reduzir a irritação da pele e troca do curativo quatro vezes ao dia

d) Uso de barreira protetora disponível, tais como solução polimérica e troca do curativo sempre que estiver úmido

18. Homem, 55 anos, portador de carcinoma espinocelular de laringe metastático para pulmão e sistema nervoso central, com ferida neoplásica maligna na região cervical à direita, medindo $11 \mathrm{~cm}$ de largura e $6 \mathrm{~cm}$ de comprimento, com presença de necrose coloração marrom em aproximadamente $\mathbf{4 0 \%}$ da área da ferida e $60 \% \mathrm{com}$ tecido aspecto vermelho vivo. Esse mesmo paciente apresenta lesão por pressão na região sacra com presença de necrose amolecida, coloração marrom em aproximadamente $\mathbf{7 0} \%$ da área da ferida e os demais $\mathbf{3 0} \%$ com tecido de granulação. Avalie o caso e escolha a opção que corresponda à conduta a ser adotada:

a) Debridar a área de necrose de ambas as feridas e utilizar produto que estimule a cicatrização das áreas de granulação, pois a conduta independe da etiologia das feridas

b) Realizar debridamento autolítico na lesão por pressão, porém, a ferida neoplásica maligna deve ter outro tipo de abordagem, devido à sua especificidade

c) Debridar cirurgicamente ambas as lesões, pois pacientes oncológicos possuem plaquetopenia e alto risco de sangramento na realização desse procedimento

d) Debridar a lesão por pressão utilizando instrumental cirúrgico, e a ferida neoplásica maligna, com uso de colagenase; para o tecido de granulação, utilizar cobertura que não provoque trauma

por meio do índice de concordância entre os avaliadores usando o W. de Kendall, com resultado de 69,3\%, indicando um bom grau de concordância. Prosseguiu-se conferindo para cada questão o valor de 1 (concordo totalmente) até 4 (discordo totalmente).

Para a taxa, utilizou-se, para o numerador, o número que representa a melhor resposta, no caso, o valor $1 \mathrm{e}$, no denominador, a média dos valores. Para calcular a concordância geral, foi calculada a taxa da concordância de cada questáo. Após o cálculo das taxas de concordância, foi calculada a concordância geral, considerando as 18 questóes do instrumento entre os 11 avaliadores, cujo resultado foi uma concordância geral igual a 0,0941. Os dados discriminados dessa pontuação e a concordância entre os juízes encontram-se na Tabela 3.

\section{DISCUSSÃO}

A proposta de construção do questionário, realizada em duas etapas com 18 indagaçóes, atendeu ao objetivo do estudo, que se tratou de agrupamento estruturado de perguntas; ou seja, um instrumento utilizado para a realização de coleta de dados. De acordo a literatura, não existe um consenso em relação à quantidade de questôes que devem compor um questionário ${ }^{16}$. Entretanto, o número de questóes deve ser o suficiente para atingir os objetivos da pesquisa, considerando que não seja um número muito elevado, evitando assim desestimular a participação dos investigados ${ }^{17}$.

Tanto na construçáo como na validação foram consideradas as equivalências semântica, idiomática, conceitual e gramatical, o que direcionou a alteração da maioria das questôes. A elaboração de um questionário deve incluir linguagem simples, direta e objetiva, com instruçôes que esclareçam a sua natureza e relevância, a fim de motivar o respondente ${ }^{12,18}$. Portanto, esse processo precisa envolver duas etapas, o desenvolvimento do instrumento e o julgamento pelos especialistas, tendo por objetivo a obtenção de consenso ${ }^{19}$.

A etapa de validação do questionário compreendeu a aplicação da técnica Delphi, considerada uma rica estratégia investigativa, dado que permite reunir opiniōes de um grupo de especialistas separados geograficamente, conduzindo a resultados concretos sobre temáticas complexas e abrangentes. É um método importante que propicia a análise de opinióes, a incitação de consensos e a identificação de temas de desacordo ${ }^{11}$. Além de ser um método fácil, acessível e de baixo custo, que permite a participação de muitos especialistas em diversas regiōes geográficas distantes ${ }^{20}$.

O uso dessa técnica permitiu obter consenso entre especialistas acerca das questóes sobre FNM quanto às equivalências supracitadas. $\mathrm{O}$ alcance desse objetivo foi possibilitado por meio da escala Likert e, também, por 
Tabela 3. Pontuação da concordância dos juízes a partir da escala de Likert quanto à avaliação do questionário sobre FNM. São Paulo, 2021

\begin{tabular}{|c|c|c|c|c|c|c|c|c|c|c|c|c|c|}
\hline Questão & $\begin{array}{c}\text { Juiz } \\
1\end{array}$ & $\begin{array}{c}\text { Juiz } \\
2\end{array}$ & $\begin{array}{c}\text { Juiz } \\
3\end{array}$ & $\begin{array}{c}\text { Juiz } \\
4\end{array}$ & $\begin{array}{c}\text { Juiz } \\
5\end{array}$ & $\begin{array}{c}\text { Juiz } \\
6\end{array}$ & $\begin{array}{c}\text { Juiz } \\
7\end{array}$ & $\begin{array}{c}\text { Juiz } \\
\mathbf{8}\end{array}$ & $\begin{array}{c}\text { Juiz } \\
9\end{array}$ & $\begin{array}{c}\text { Juiz } \\
10\end{array}$ & $\begin{array}{c}\text { Juiz } \\
11 \\
\end{array}$ & Média & $\begin{array}{c}\text { Concordância } \\
(\%)\end{array}$ \\
\hline$N^{\circ} 01$ & 1 & 2 & 2 & 1 & 1 & 1 & 1 & 1 & 1 & 1 & 1 & 1.182 & 84,62 \\
\hline$N^{\circ} 02$ & 1 & 1 & 1 & 1 & 1 & 1 & 4 & 1 & 1 & 1 & 1 & 1.273 & 78,57 \\
\hline$N^{\circ} 03$ & 1 & 2 & 1 & 1 & 1 & 1 & 3 & 2 & 2 & 1 & 2 & 1.545 & 64,71 \\
\hline$N^{\circ} 04$ & 2 & 3 & 1 & 1 & 1 & 1 & 3 & 2 & 2 & 1 & 1 & 1.636 & 61,11 \\
\hline$N^{\circ} 05$ & 1 & 4 & 1 & 1 & 1 & 1 & 3 & 1 & 2 & 1 & 1 & 1.545 & 64,71 \\
\hline$N^{\circ} 06$ & 1 & 1 & 1 & 1 & 1 & 1 & 3 & 1 & 1 & 1 & 1 & 1.182 & 84,62 \\
\hline$N^{\circ} 07$ & 1 & 2 & 2 & 1 & 1 & 1 & 3 & 1 & 2 & 1 & 1 & 1.455 & 68,75 \\
\hline$N^{\circ} 08$ & 1 & 2 & 3 & 1 & 1 & 1 & 2 & 1 & 2 & 1 & 1 & 1.455 & 68,75 \\
\hline $\mathbf{N}^{\circ} 09$ & 1 & 3 & 1 & 2 & 1 & 1 & 2 & 1 & 2 & 1 & 1 & 1.455 & 68,75 \\
\hline $\mathbf{N}^{\circ} 10$ & 2 & 1 & 1 & 1 & 1 & 1 & 2 & 1 & 1 & 1 & 1 & 1.182 & 84,62 \\
\hline$N^{\circ} 11$ & 3 & 1 & 1 & 1 & 4 & 1 & 1 & 1 & 1 & 1 & 1 & 1.455 & 68,75 \\
\hline$N^{\circ} 12$ & 1 & 2 & 1 & 1 & 1 & 1 & 2 & 1 & 2 & 1 & 1 & 1.273 & 78,57 \\
\hline$N^{\circ} 13$ & 1 & 4 & 1 & 1 & 1 & 4 & 1 & 2 & 2 & 1 & 1 & 1.727 & 57,89 \\
\hline$N^{\circ} 14$ & 4 & 4 & 2 & 1 & 1 & 1 & 4 & 1 & 2 & 1 & 1 & 2.000 & 50,00 \\
\hline$N^{\circ} 15$ & 4 & 1 & 1 & 1 & 1 & 1 & 2 & 2 & 2 & 1 & 1 & 1.545 & 64,71 \\
\hline$N^{\circ} 16$ & 4 & 4 & 2 & 1 & 1 & 1 & 1 & 2 & 1 & 1 & 1 & 1.727 & 57,89 \\
\hline$N^{\circ} 17$ & 1 & 4 & 1 & 1 & 1 & 1 & 2 & 1 & 2 & 1 & 1 & 1.455 & 68,75 \\
\hline$N^{\circ} 18$ & 3 & 2 & 1 & 1 & 1 & 1 & 1 & 1 & 2 & 1 & 1 & 1.364 & 73,33 \\
\hline
\end{tabular}

um espaço para o detalhamento de sugestôes. Essa escala requer que $o$ avaliador indique seu grau de concordância ou discordância com declaraçóes relativas ao que se está medindo ${ }^{13}$. As vantagens relacionadas à tal escala incluem a simplicidade de construção e o uso de afirmações que não estão implicitamente ligadas à atitude estudada, permitindo a inclusão de qualquer item que se mostre coerente com o resultado final ${ }^{21}$.

A validação envolveu 11 especialistas, sendo dois estomaterapeutas e nove pós-graduados stricto sensu, que realizaram suas pesquisas na área da Oncologia e no tratamento de pacientes portadores de feridas.

$\mathrm{Na}$ literatura, náo existe consenso quanto ao número ideal de juízes para avaliação de instrumentos ${ }^{13}$. Entretanto, é recomendada a participação de três a dez juízes na validação de conteúdo, tendo em vista a experiência acumulada e pelo fato de o julgamento ser feito individualmente ${ }^{22}$. A evidência de validade do conteúdo de instrumento usado em pesquisa, por dois ou mais avaliadores, exclui a subjetividade e atribui confiabilidade aos resultados ${ }^{23}$.

Importante salientar que a escolha de experts ancora as pesquisas que utilizam essa abordagem metodológica. Portanto, a escolha inadequada dos critérios de seleção para compor o comitê de juízes interfere na veracidade dos resultados, considerando que caberá a esses profissionais a funçáo de julgar o quanto cada questáo é relevante quanto ao propósito de testar o conhecimento do enfermeiro especialista em Oncologia sobre o tema FNM ${ }^{24}$.

Em relação aos especialistas, observa-se que a maioria $(81,8 \%)$ possui mestrado e doutorado. Esse dado é reforçado com o resultado utilizando os critérios propostos por Fehring ${ }^{10}$, obtendo média de 11 pontos. De acordo com a literatura, deve-se obter uma pontuação mínima de cinco pontos para ser considerado apto para compor o comitê de especialistas para o processo de validaçáo de conteúdo ${ }^{25,26}$.

Em relação ao tempo de experiência na Oncologia, observa-se que $45,4 \%$ possuem entre 2 e 4 anos, porém, $18,1 \%$ têm mais de 17 anos na área. Essa variável é um importante ponto na identificação de um expert, considerando a possibilidade desse profissional auxiliar no alcance do objetivo do estudo, uma vez que a experiência clínica aumenta proporcionalmente com o tempo de prática. Tal fator possui forte influência na tomada de decisão $0^{27}$.

Portanto, quanto maior for a titulação o número de publicaçôes e o tempo de experiência clínica, mais experto o profissional seráa ${ }^{24}$.

Observa-se um bom índice de concordância $(0,0941)$ com o uso do W. de Kendall. Esse método calcula a concordância entre três ou mais sujeitos, considerando 
como eles classificam uma série de temas de acordo com uma característica particular ${ }^{28}$.

Importante ressaltar que a realidade imposta pela inviabilidade da cura determinada pela doença oncológica, tendo como sentenciação a náo cicatrização da ferida, gera frustação para o enfermeiro, o que pode resultar em um desinteresse sobre o tema $\mathrm{FNM}^{29}$. Em um estudo realizado em âmbito nacional, com o objetivo de investigar a produção científica sobre "feridas crônicas", foram apontadas as FNM como "as lesóes de menor interesse", com apenas um trabalho que correspondeu a $2 \%$ da $\operatorname{amostra}^{30}$.

O tema FNM é complexo e pouco abordado nas áreas de pesquisa e ensino dentro da especialidade oncológica. No entanto, é importante compreender o conhecimento possuído pelo enfermeiro tanto para aqueles que estão em campo prático como os em formaçáo, uma vez que esse profissional é o responsável pelo processo de cuidado, o qual precede à comunicação efetiva, tendo como elementos primordiais, para tanto, a formaçáo de vínculo e a relação de confiança entre o paciente e a equipe de enfermagem ${ }^{29}$.

\section{CONCLUSÃO}

Este estudo apresenta como limitação a falta de outras variáveis quanto às características sociodemográficas do comitê de juízes, como idade, tempo de exercício na profissão, tipo de relação com o tema (assistência, pesquisa e ensino), considerados pontos positivos para a seleçáo de um expert.

O presente estudo contribui para a área de Enfermagem Oncológica tanto no que tange às instituiçóes de ensino que possuem o programa de pós-graduação em Oncologia como às instituiçóes de saúde, com o intuito de direcionar o desenvolvimento de programas de educação permanente, uma vez que possibilita a avaliação do conhecimento dos profissionais sobre um tema de extrema relevância para a qualidade de vida do paciente oncológico. Porém, é importante a continuidade da aplicação do questionário para enfermeiros especialistas em Oncologia e/ou atuantes em instituiçóes dessa especialidade.

\section{CONTRIBUIÇÕES}

Ambas as autoras contribuíram substancialmente na concepção e/ou planejamento do estudo; na obtenção, análise e/ou interpretação dos dados; na redação e revisão crítica; e aprovaram a versão final a ser publicada.

\section{DECLARAÇÃO DE CONFLITO DE INTERESSES}

Nada a declarar.

\section{FONTES DE FINANCIAMENTO}

Não há.

\section{REFERÊNCIAS}

1. Instituto Nacional de Câncer José Alencar Gomes da Silva. $A B C$ do câncer: abordagens básicas para o controle do câncer [Internet]. 6. ed. rev. atual. Rio de Janeiro: INCA; 2020 [acesso 2021 dec 22]. Disponível em: https://www.inca.gov.br/sites/ufu.sti.inca.local/files// media/document//livro-abc-6-edicao-2020.pdf

2. Instituto Nacional de Câncer José Alencar Gomes da Silva. Estimativa 2020: incidência de câncer no Brasil [Internet]. Rio de Janeiro: INCA; 2019 [acesso 2020 ago 12]. Disponível em: https://www.inca.gov.br/sites/ufu. sti.inca.local/files//media/document//estimativa-2020incidencia-de-cancer-no-brasil.pdf

3. Souza MAO, Souza NR, Melo JTS, et al. Escalas de avaliaçáo de odor em feridas neoplásicas: uma revisão integrativa. Rev Bras Enferm. 2018;71(5):2552-60. doi: https://doi.org/10.1590/0034-7167-2017-0428

4. Matsubara MGS. Feridas neoplásicas. In: Matsubara MGS, Villela DL, Hashimoto SY, et al. Feridas e estomas em oncologia: uma abordagem interdisciplinar. São Paulo: Lemar; 2012. p. 33-46.

5. Agra G, Medeiros MVS, Brito DTF, et al. Conhecimento e prática de enfermeiros no cuidado a pacientes com feridas tumorais malignas. Rev Cuid. 2017;8(3):1849-62. doi: http://doi.org/10.15649/cuidarte.v8i3.441

6. Gozzo TO, Tahan FP, Andrade M, et al. Ocorrência e manejo de feridas neoplásicas em mulheres com câncer de mama avançado. Esc. Anna Nery. 2014;18(2):2706. doi: https://doi.org/10.5935/1414-8145.20140039

7. Agra G, Costa MML. Feridas neoplásicas. In: Campos MGCA, Souza ATO, Vasconcelos JMB, et al., organizadoras. Feridas complexas e estomias: aspectos preventivos e manejo clínico. Joáo Pessoa, PB: Ideia; 2016. p. 302-20.

8. Azevedo IC, Costa RKS, Holanda CSM, et al. Conhecimento de enfermeiros da estratégia saúde da família sobre avaliaçáo e tratamento de feridas oncológicas. Rev Bras Cancerol. 2014;60(2):11927. doi: https://doi.org/10.32635/2176-9745. RBC. $2014 \mathrm{v} 60 \mathrm{n} 2.476$

9. Fehring RJ. The Fehring model. In: Carrol-Jonhnson RM, Paquette M, editors. Classification of nursing diagnoses: proceedings of the tenth conference. Philadelphia: Limppincott; c1994. p. 55-62.

10. Fehring RJ. Methods to validate nursing diagnoses [Internet]. [place unknown]: e-Publications@Marquette; 1987 Jan 11 [cited 2019 Apr 12]. Available from: https:// epublications.marquette.edu/cgi/viewcontent.cgi?article $=1026 \&$ context=nursing_fac 
11. Marques JBV, Freitas D. Método DELPHI: caracterização e potencialidades na pesquisa em Educação. ProPosiçóes 29. 2018;29(2):389-415. doi: https://doi. org/10.1590/1980-6248-2015-0140

12. Antunes MM. Técnica Delphi: metodologia para pesquisas em educação no Brasil. Rev Educ PUC-Camp [Internet]. 2014 [acesso 2019 abr 24];19(01):63-71. Disponível em: http://periodicos.puc-campinas. edu. $\mathrm{br} / \mathrm{seer} /$ index.php/reveducacao/ article/view/2616/1894

13. Baker MJ, organizador. Administração de marketing. 5. ed. Rio de Janeiro: Elsevier; 2005.

14. Beaton DE, Bombardier C, Guillemin F, et al. Guidelines for the process of cross-cultural adaptation of self-report measures. Spine (Phila Pa 1976). 2000;25(24):3186-91. doi: https://doi.org/10.1097/00007632-20001215000014

15. Conselho Nacional de Saúde (BR). Resolução no 510, de 7 de abril de 2016. Dispóe sobre as normas aplicáveis a pesquisas em Ciências Humanas e Sociais cujos procedimentos metodológicos envolvam a utilização de dados diretamente obtidos com os participantes ou de informaçóes identificáveis ou que possam acarretar riscos maiores do que os existentes na vida cotidiana, na forma definida nesta Resolução. Diário Oficial da União. 2016 maio 24; Edição 98, Seção I:44.

16. Coluci MZO, Alexandre NMC, Milani D. Construção de instrumentos de medida na área da saúde. Ciênc Saúde Coletiva. 2015;20(3):925-36. doi: https://doi. org/10.1590/1413-81232015203.04332013

17. Chaer G, Diniz RRP, Ribeiro EA. A técnica do questionário na pesquisa educacional. Evidência [Internet]. 2011 [acesso 2021 jun 12];7(7):251-66. Disponível em: http://www.educadores.diaadia.pr.gov. br/arquivos/File/maio2013/sociologia_artigos/pesqusia_ social.pdf

18. Prodanov CC, Freitas EC. Metodologia do trabalho científico: métodos e técnicas da pesquisa e do trabalho acadêmico. 2. ed. Novo Hamburgo, RS: Feevale; 2013.

19. Mendes KGL. A participação das enfermeiras na gestão de custos em organizaçóes hospitalares [tese na Internet]. São Paulo: Escola de Enfermagem; 2011 [acesso 2019 abr 11]. Disponível em: http://www.teses.usp.br/teses/ disponiveis/7/7140/tde-03102011-092928/pt-br.php

20. Lima-Rodríguez JS, Lima-Serrano M, Jiménez-Picón N, et al. Validação de conteúdo da escala de auto-percepção do estado da saúde familiar utilizando a técnica Delphi. Rev Latino-Am Enfermagem. 2013;21(2):595-603. doi: https://doi.org/10.1590/S0104-11692013000200017

21. Mattar FN. Pesquisa de marketing. 6. ed. São Paulo: Atlas; 2005.
22. Nicole AG, Tronchin DMR. Indicadores para avaliação do acesso vascular de usuários em hemodiálise. Rev Esc Enferm. 2011;45(1):206-14. doi: https://doi. org/10.1590/S0080-62342011000100029

23. Carillo de Gea JMC, Fernández-Alemán JL, Sánchez Garcia AB. Computer-based nursing education: an integrative review of empirical studies. J Nurs Educ Pract. 2012;2(3):162-72. doi: https://doi.org/10.5430/ jnep.v2n3p162

24. Galdeano LE, Rossi LA. Validação de conteúdo diagnóstico: critérios para seleção de expertos. Ciênc Cuid Saúde. 2006;5(1):60-6. doi: https://doi.org/10.4025/ cienccuidsaude.v5i1.5112

25. Dorigan GH, Guirardello EB. Tradução e adaptação cultural do Newcastle Satisfaction with Nursing Scales para a cultura brasileira. Rev Esc Enferm. 2013;47(3):562-8. doi: https://doi.org/10.1590/S0080623420130000300006

26. Gonçalves MCS, Brandão MAG, Duran ECM. Validação das características definidoras do diagnóstico de enfermagem conforto prejudicado em oncologia. Acta Paul Enferm. 2016;29(1):115-24. doi: https://doi. org/10.1590/1982-0194201600016

27. Pompeo DA, Rossi LA, Paiva L. Validação de conteúdo do diagnóstico de enfermagem náusea. Rev Esc Enferm. 2014;48(1):49-57 doi: https://doi.org/10.1590/S0080623420140000100006

28. Siegel S, Castellan NJ Jr. Estatística não paramétrica para ciências do comportamento. 2. ed. Sáo Paulo: Bookman; 2006.

29. Schmidt FMQ, Firmino F, Lenza NFB, et al. Conhecimento da equipe de enfermagem sobre cuidados com pacientes com feridas neoplásicas. Rev Bras Enferm. 2020;73(1):e20170738. doi: https://doi. org/10.1590/0034-7167-2017-0738

30. Brito KKG, Sousa MJ, Sousa ATO, et al. Chronic injuries: nursing approach in the post graduate scientific production. J Nurs UFPE On Line. 2013;7(2):41421. doi: https://doi.org/10.5205/1981-8963v7i2a10250p414-421-2013 